\title{
An evaluation method of the sustainability of water resource in karst region: a case study of Zunyi, China
}

\author{
Bo $\mathrm{Li}^{1,2} \cdot$ Ganlu Wang ${ }^{2} \cdot$ Hanghang Ding ${ }^{2} \cdot$ Yulong Chen ${ }^{3}$
}

Received: 17 December 2014/ Accepted: 27 October 2015/Published online: 7 November 2015

(C) The Author(s) 2015. This article is published with open access at Springerlink.com

\begin{abstract}
Water resource is of great significance to the survival and development of human. However, the water resource system in karst regions is sensitive to external interference owing to the special geological processes which cause soil impoverishment, severe rocky desertification and large topographic height difference. Therefore, evaluating the sustainability of the water resource in karst regions is beneficial to reasonably use and protect water resource. This paper puts forward to evaluate the water resource from four aspects, including water resources system, water requirement system, ecosystem and social economic system. Moreover, on this basis, 18 evaluation indexes were selected to construct the sustainability evaluation index system and method. This method was used to evaluate the sustainability of the water resource in the typical karst region-Zunyi, Guizhou province, China, and was verified according to the actual situation in the research area. All these provide reference for the
\end{abstract}

Bo $\mathrm{Li}$

libo1512@163.com

Ganlu Wang

47850901@qq.com

Hanghang Ding

1679760386@qq.com

Yulong Chen

673054399@qq.com

1 Key Laboratory of Karst Environment and Geohazard Prevention, Ministry of Education, Guizhou University, Guiyang 550000, Guizhou, China

2 College of Resource and Environmental Engineering, Guizhou University, Guiyang 550000, Guizhou, China

3 Department of Civil Engineering, University of Tokyo, Tokyo 113-8656, Japan evaluation of the sustainability of the water resource in similar regions.

Keywords Karst region - Water resource - Evaluation index system $\cdot$ Sustainability $\cdot$ Evaluation

\section{Introduction}

The water resource is the basic resources for controlling the ecological environment and the material base for social development. The World Water Resources Comprehensive Assessment (1997.1) of the United Nations reported that water crisis would seriously restrict global society and economy development in the twenty-first century, and might lead to conflicts among countries (Simonovic et al. 1995; Loucks 2000; Giacomoni and Zechman 2011). Currently, the water crisis in all the countries has not been solved fundamentally and even become more serious. Accordingly, performing relative studies on the sustainability of the water resource is beneficial to the reasonable utilization and protection of water resource (Rijsberman et al. 2000).

Currently, there are a lot of researchers studying on water resources sustainability; the Fuzzy UTASTAR multicriteria analysis method (based on linear programing) has been used for sustainability evaluation by Haider et al. (2015). The groundwater resource carrying capacity of the irrigation areas is evaluated using the improved catastrophe evaluation method by Xiao et al. (2011). To evaluate the long-term sustainability of water withdrawals in the United States, the magnitudes of human withdrawals from surface water and ground water sources and the stored water requirements during the warmest months of the year were evaluated by Roy, SB (Roy et al. 2015). Kuzdas et al. 
(2014) presented a criteria-based and participatory sustainability appraisal of water governance in a region with such characteristics-the dry tropics of NW Costa Rica.

Previous researches on the evaluation of the sustainability of the water resource mainly focus on non-karst regions, while rarely evaluate the sustainability of that in karst regions. With large topographic height difference and developed karst channels, karst regions are generally covered with thin overlying soil (Chu et al. 2008; Zhang et al. 2004). These characteristics lead to these regions which have more abundant water resource underground than on the ground; moreover, the water resource system responds more sensitively to the changes in the surrounding environment. For the sustainability of the water resource, except for the influence of the fixed factors of water, it is also related to the water requirement, ecological environment and social economy in the region. Considering this, studying the sustainability of water resource merely from one aspect cannot reflect the whole situation. Therefore, in view of water resource system, water requirement system, ecosystem and social economic system, the evaluation index system for the sustainability of the water resource in the karst region is constructed. Based on the system, the typical karst mountainous area, that is, Zunyi, in Guizhou, China, is served as an example to evaluate the sustainability of water resource.

\section{Evaluation index system}

The evaluation index system for the sustainability of the water resource in the karst region is complicated, thus attention has to be paid to two points in the selection of evaluation indexes. Firstly, the evaluation indexes are supposed to present the key factors affecting the sustainability of the water resource; secondly, the selected indexes are operable (Bossel 1999). Therefore, from four aspects including water resources system, water requirement system, ecosystem and social economic system, this paper selected corresponding indexes to establish the evaluation index system.

\section{Water resource system}

The water resource system refers to the factors influencing the water resource quantity in a natural state, mainly including four ones. First is the annual mean precipitation. As the main source of water, precipitation can reflect the water resource quantity in the research area. Second is the annual mean evaporation which means the amount of moisture evaporated to air in a certain period. Thirdly, water production modulus presents the ratio of total water resource to the total area of the region. Fourth is a drought index, which mirrors the degree of drought and is generally defined as the ratio of annual evaporation to annual precipitation.

\section{Water requirement system}

The water requirement system presents the requirement degree of water resource for social development. It is primarily influenced by the following five factors: firstly, it is affected by the exploitation and utilization rate of water resource, which shows the percentage of annual water consumption in the total water resource. The second one is the development difficulty coefficient of water resource. It is an important index for measuring the development difficulty of the water resource. The third influencing factor is water consumption per capita, which is the ratio of water consumption to total population in the research area. Fourth is the proportion of industrial water. It presents the ratio of industrial water consumption to total water consumption in a certain region. The fifth is the proportion of agricultural water, which shows the ratio of water used for agricultural irrigation to total water used in a certain region.

\section{Ecosystem}

Aiming at the present ecological problems caused by the shortage and irrational utilization of water in the karst region, the relation between the ecological environment and water resource has to be studied. The main factors influencing the sustainability evaluation of the water in the ecosystem are as follows. First is the average standardreaching percentage of water quality. It is the percentage of the quantity of water reaching the quality standard in the total detected water. Second is the intensity coefficient of karst development which determines the capacity of groundwater for receiving rainfall and the degree of being polluted. Thirdly, rocky desertification is the ratio of rocky desertification area to the total area of this region. Rocky desertification results in the reduction capacity of soil for water conservation. Fourth is the overburden thickness which is the thickness of surface soil. Different overburden thicknesses correspond to the different capacities of natural degradation of pollutant composition and pollution infiltration. The fifth influencing factor is the vegetation coverage, which presents the ratio of forest cover to the total area of the research region.

\section{Social economic system}

Social economy is closely related to the sustainability of the water resource. It is mainly influenced by the following factors: firstly, natural growth rate of population, which is an important index for reflecting the development speed of 
Table 1 Evaluation index system for the sustainability of water resource in the karst region

\begin{tabular}{|c|c|c|c|c|}
\hline Target & \multicolumn{4}{|c|}{ Evaluation of the sustainability of water resource in the karst region and its influencing factors $(A)$} \\
\hline $\begin{array}{l}\text { Criteria } \\
\quad \text { layer } B\end{array}$ & $\begin{array}{l}\text { Water resources } \\
\text { system }\left(B_{1}\right)\end{array}$ & Water requirement system $\left(B_{2}\right)$ & Ecosystem $\left(B_{3}\right)$ & Social economic system $\left(B_{4}\right)$ \\
\hline \multirow[t]{5}{*}{$\begin{array}{l}\text { Index } \\
\quad \text { layer } C\end{array}$} & $\begin{array}{l}\text { Annual mean } \\
\quad \text { precipitation }\left(C_{1}\right)\end{array}$ & $\begin{array}{l}\text { Exploitation and utilization rate of } \\
\text { water resource }\left(C_{5}\right)\end{array}$ & $\begin{array}{l}\text { Average standard-reaching rate of } \\
\text { water quality }\left(C_{10}\right)\end{array}$ & $\begin{array}{l}\text { Natural growth rate of population } \\
\left(C_{15}\right)\end{array}$ \\
\hline & $\begin{array}{l}\text { Annual mean } \\
\quad \text { evaporation }\left(C_{2}\right)\end{array}$ & $\begin{array}{l}\text { Development } \\
\text { difficulty coefficient of water } \\
\text { resource }\left(C_{6}\right)\end{array}$ & Rocky desertification rate $\left(C_{11}\right)$ & $\begin{array}{l}\text { Water consumption per unit GDP } \\
\qquad\left(C_{16}\right)\end{array}$ \\
\hline & $\begin{array}{l}\text { Water production } \\
\text { modulus }\left(C_{3}\right)\end{array}$ & Water consumption per capita $\left(C_{7}\right)$ & $\begin{array}{l}\text { Intensity coefficient of karst } \\
\text { development }\left(C_{12}\right)\end{array}$ & $\begin{array}{l}\text { Perfect degree of regulations related } \\
\text { to water resource }\left(C_{17}\right)\end{array}$ \\
\hline & Drought index $\left(C_{4}\right)$ & Proportion of industrial water $\left(C_{8}\right)$ & Overburden thickness $\left(C_{13}\right)$ & Mean life expectancy $\left(C_{18}\right)$ \\
\hline & & $\begin{array}{l}\text { Proportion of agricultural water } \\
\left(C_{9}\right)\end{array}$ & Vegetation coverage $\left(C_{14}\right)$ & \\
\hline
\end{tabular}

population and formulating population plan. Secondly, water consumption per unit gross domestic product (GDP), which is the ratio of the total water consumption to the urban GDP. Thirdly, the perfect degree of regulations related to water resource, which mirrors the perfect degree of laws and regulations related to water resource in this region. Fourthly, average life expectancy, which presents the average lifetime of people in the research region.

Based on the above analysis, the research object is divided into three layers. As the ultimate propose, the evaluation of the sustainability of water resource in the karst region is acted as the target layer ( $A$ layer) of the model; though water resources system, water requirement system, ecosystem and social economic system determine the possibility of sustainability, their effects have to be reflected by concrete indexes, thus serving as the criteria layer ( $B$ layer); the concrete main controlling factors compose the index layer ( $C$ layer) of the model (Table 1$)$.

\section{Methods for evaluating the sustainability of the water resource in the karst region}

\section{Calculation for the comprehensive indexes of the sustainability of water resource}

The indexes in the sustainability evaluation system of water resource present the sustainability of the water resource from different aspects, so the influencing effects of each index have to be comprehensively considered. In this paper, using the multi-index linear weighted function, the evaluation model is as follows:

$A_{i}=\sum C_{i k} \times W_{i k}$

where $A$ presents the comprehensive evaluation value of the sustainability of water resource, $C_{i k}$ shows the index value of the $k$ th factor in the $i$ th subsystem, while $W_{i k}$ is the weight of the $k$ th index in the $i$ th subsystem.

The index values are quantized based on the standard in Table 2. While according to the effect of index values on the system, directional indexes are divided into positive and inverse ones. Then, suppose that $a_{1}<a_{2}<a_{3}<a_{4}$ and $b_{1}<b_{2}<b_{3}<b_{4}$ are the grading scores of the positive and reverse indexes, respectively.

Based on the scoring standard of the indexes in Table 2, linear index quantization is used to quantize the indexes. Suppose $P$ is the score of the indexes and $x$ presents the actual values of the indexes, the following index quantization formula is obtained.

1. I-grade index

For the positive index, when $x \leq a_{1}, p=1$.

For the reverse index, $p=1$ when $x \geq b_{4}$.

2. II-grade index

$p=1+\left(x-a_{1}\right) \frac{1}{a_{2}-a_{1}}$, when $x$ is positive index;

$p=1+\left(b_{4}-x\right) \frac{1}{b_{4}-b_{3}}$, when $x$ is reverse index.

3. III-grade index

$p=2+\left(x-a_{2}\right) \frac{1}{a_{3}-a_{2}}$, when $x$ is positive index;

$p=2+\left(b_{3}-x\right) \frac{1}{b_{3}-b_{2}}$, when $x$ is reverse index.

4. IV-grade index

$p=3+\left(x-a_{3}\right) \frac{1}{a_{4}-a_{3}}$, when $x$ is positive index;

$p=3+\left(b_{2}-x\right) \frac{1}{b_{2}-b_{1}}$, when $x$ is reverse index.

5. V-grade index

For the positive indexes, when $x \geq a_{4}, p=4$.

For the reverse indexes, $p=4$ when $x \leq b_{1}$.

\section{Methods for determining the weights of indexes}

This paper employs the analysis hierarchy process (AHP) to determine the weights of indexes for factors. Proposed by American operation researcher and professor Saaty in 
Table 2 The marking standard of the sustainability evaluation index of water resource in karst regions

\begin{tabular}{cllllll}
\hline Category & Range & $\begin{array}{l}\text { Weaker } \\
\text { sustainability } \\
\text { I grade }\end{array}$ & $\begin{array}{l}\text { Weak } \\
\text { sustainability } \\
\text { II grade }\end{array}$ & $\begin{array}{l}\text { Moderate } \\
\text { sustainability } \\
\text { III grade }\end{array}$ & $\begin{array}{l}\text { Strong } \\
\text { sustainability } \\
\text { IV grade }\end{array}$ & $\begin{array}{l}\text { Stronger } \\
\text { sustainability } \\
\text { V grade }\end{array}$ \\
\hline $\begin{array}{c}\text { Positive } \\
\text { indexes }\end{array}$ & $\begin{array}{c}\text { Value } \\
\text { range }\end{array}$ & $\leq a_{1}$ & $a_{1}-a_{2}$ & $a_{1}-a_{2}$ & $a_{1}-a_{2}$ & $\geq a_{4}$ \\
$\begin{array}{c}\text { Reverse } \\
\text { indexes }\end{array}$ & $\begin{array}{c}\text { Score range } \\
\text { Value }\end{array}$ & 1 & $1-2$ & $2-3$ & $3-4$ & 4 \\
& range & $\geq b_{4}$ & $b_{3}-b_{4}$ & $b_{2}-b_{3}$ & $b_{1}-b_{2}$ & $\leq b_{1}$ \\
& Score range & 1 & $1-2$ & $2-3$ & $3-4$ & 4 \\
\hline
\end{tabular}

the 1980s, this method is a practical decision-making method for multi-schemes or multi-objectives. The concrete procedures are as follows (Saaty 1977, 1980): The hierarchical structure of the system is firstly established by analyzing the relation of factors. Next, the 1-9 scale method is utilized to construct the judgment matrix through pairwise comparison. Then, single ordering and consistency check are conducted to the hierarchies. Finally, hierarchy general ranking and consistency check are performed.

\section{Application example}

\section{Research situation}

\section{Position}

Located in the southwest of China and the north of Guizhou province, namely, $105^{\circ} 36^{\prime}-108^{\circ} 13^{\prime} \mathrm{E}$ and $27^{\circ} 8^{\prime}$ $-29^{\circ} 12^{\prime} \mathrm{N}$, Zunyi is situated in the slope zone where the terrain changes from Yun-Gui plateau to Hunan hill and Sichuan basin. With large topographic relief and complex landforms, Zunyi, at an altitude of $1000-1500 \mathrm{~m}$, is distributed with extensive corrosion landform (karst landform) which accounts for $75 \%$ of total land area (Fig. 1).

\section{Meteorology and hydrology}

Situated in the subtropical humid monsoon climate zone, Zunyi shows an annual mean precipitation of $1167.3 \mathrm{~mm}$. Moreover, the maximal and minimal annual precipitations are 1498.4 and $871.0 \mathrm{~mm}$ separately. The precipitation here generally occurs from May to September, which occupies 59-74\% of the annual precipitation. The rivers in the research region belong to the Yangtze River with the basin area of 30,763 square kilometers.

\section{Hydrogeology}

In the research region, the outcropping strata include those from Sinian system to Quaternary system, except for Silurian system, Devonian system, Carboniferous system, upper Jurassic series and Tertiary system. The groundwater is mainly carbonate rock karst water, which is mainly supplied from the atmospheric precipitation. Afterwards, under the influence of surface hydrographic net and lithology as well as tectonics, the groundwater flows out as springs or underground rivers through the cracks and pipelines developed in the rock mass.

4. Current situations of social economy and exploration of water resource

At the end of 2014, there were 6.1549 million permanent residents in the research area. The regional gross product and total financial income were 187.436 billion yuan and 41.266 billion yuan, respectively. Urban and rural per capita disposable incomes were 22,728 and 8365 yuan separately. The total surface water amount and groundwater quantity in the research area were 21.48 billion cubic meters and 4.872 billion cubic meters, respectively. While the total water used in this year was 2.15 billion cubic meters in which 1.962 billion cubic meters were surface water.

\section{Ecological environment}

As a mountainous area characterized by bare karsts, this region has widely distributed carbonate rocks and intensely developed karsts. In addition, karst forms including sinkhole, doline, depression, etc. are densely distributed. The groundwater is accumulated and flows through cracks, pipelines, karst carves, etc. The forest coverage in Zunyi city is about $53.08 \%$; besides, the karst area accounts for $75 \%$ of total area of Zunyi and the rocky desertification area takes up $18.79 \%$ of the karst area.

\section{Quantization for indexes}

The indexes are quantized using the method proposed in the third section, and then the results are graded according to the standard with five grades in Table 2. The obtained quantization results of the indexes in the research region are presented in Table 3. 


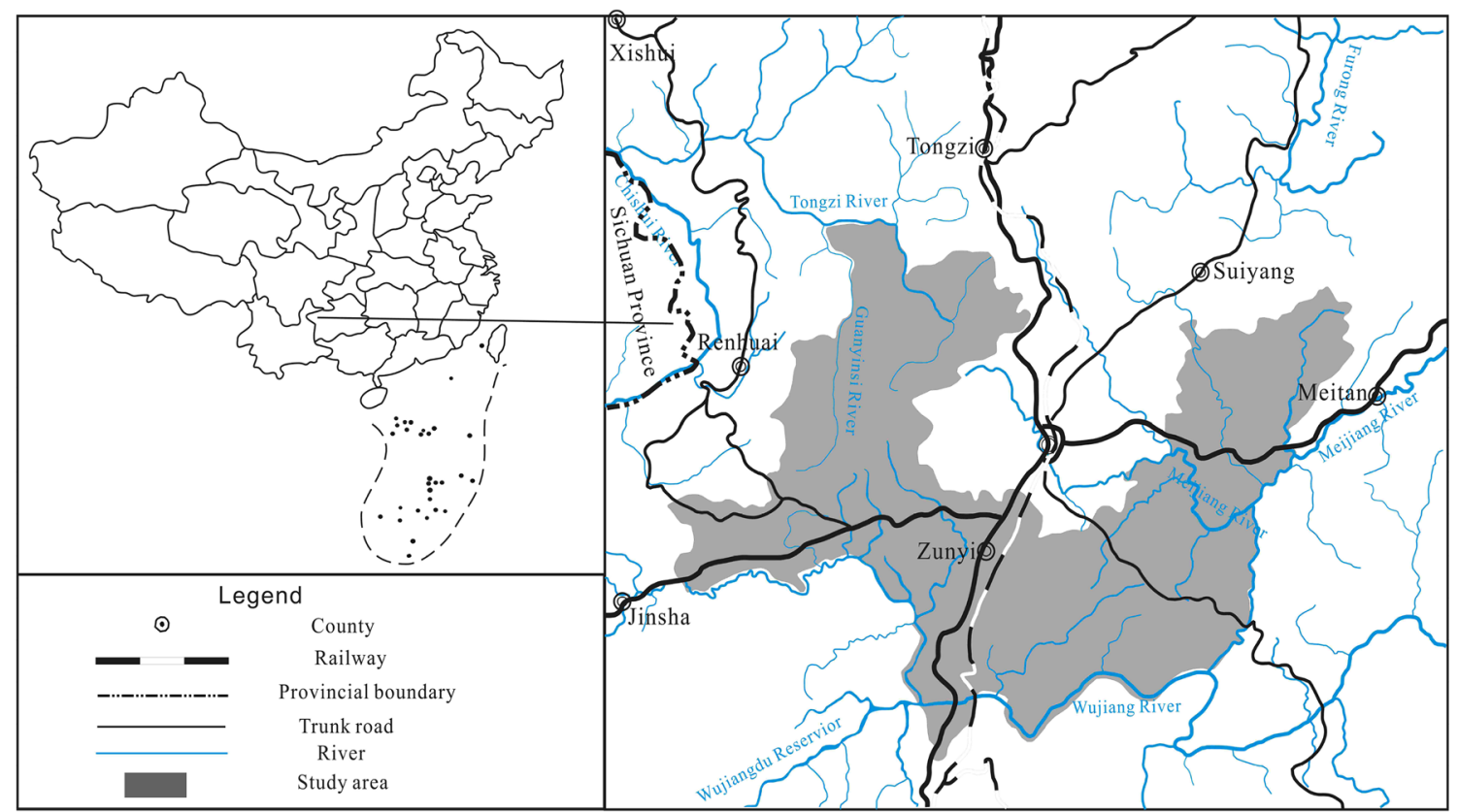

Fig. 1 Site location

Table 3 The quantization results of the indexes

\begin{tabular}{|c|c|c|c|}
\hline Indexes & $\begin{array}{l}\text { Quantized } \\
\text { values }\end{array}$ & Indexes & $\begin{array}{l}\text { Quantized } \\
\text { values }\end{array}$ \\
\hline Annual mean precipitation $\left(C_{1}\right)$ & 2.00 & $\begin{array}{l}\text { Average standard-reaching percentage of water quality } \\
\left(C_{13}\right)\end{array}$ & 3.10 \\
\hline Annual mean evaporation $\left(C_{2}\right)$ & 1.59 & Rocky desertification $\left(C_{10}\right)$ & 1.16 \\
\hline Water production modulus $\left(C_{3}\right)$ & 2.11 & Intensity coefficient of karst development $\left(C_{14}\right)$ & 1.26 \\
\hline Drought index $\left(C_{4}\right)$ & 1.55 & Overburden thickness $\left(C_{12}\right)$ & 1.05 \\
\hline $\begin{array}{l}\text { Exploitation and utilization rate of water resource } \\
\left(C_{5}\right)\end{array}$ & 2.10 & Vegetation coverage $\left(C_{11}\right)$ & 2.55 \\
\hline $\begin{array}{l}\text { Development difficulty coefficient of water resource } \\
\qquad\left(C_{8}\right)\end{array}$ & 1.20 & Population growth rate $\left(C_{15}\right)$ & 2.40 \\
\hline Water consumption per capita $\left(C_{7}\right)$ & 1.52 & Water consumption per unit $\operatorname{GDP}\left(C_{16}\right)$ & 1.40 \\
\hline Proportion of industrial water $\left(C_{8}\right)$ & 2.00 & $\begin{array}{l}\text { Perfect degree of regulations related to water resource } \\
\left(C_{17}\right)\end{array}$ & 1.20 \\
\hline Proportion of agricultural water $\left(C_{9}\right)$ & 1.92 & Mean life expectancy $\left(C_{18}\right)$ & 2.63 \\
\hline
\end{tabular}

\section{Determination of the weights of the indexes}

According to the analysis on the main controlling factors on the vulnerability of water resource, the relative importance of each factor is evaluated by experts in the field through expert evaluation method, thus an evaluation set of the influencing factors is obtained. On this basis, the judgment matrix for evaluating the sustainability of the water resource based on the AHP method in the karst region is established. The weights of the indexes in the

Table 4 Judgment matrix $A \sim B_{i}(i=1-4)$

\begin{tabular}{llllll}
\hline$A$ & $B_{1}$ & $B_{2}$ & $B_{3}$ & $B_{4}$ & $\begin{array}{l}W(A / \\
\left.B_{4}\right)\end{array}$ \\
\hline$B_{1}$ & 1 & 2 & 2 & 2 & 0.39521 \\
$B_{2}$ & $1 / 2$ & 1 & 2 & 2 & 0.27807 \\
$B_{3}$ & $1 / 2$ & $1 / 2$ & 1 & 1 & 0.16336 \\
$B_{4}$ & $1 / 2$ & $1 / 2$ & 1 & 1 & 0.16336 \\
\hline$\lambda_{\max }=4$, CI & 0.0202, & $\mathrm{CR}=0.02246<0.1$ & &
\end{tabular}


Table 5 Calculation results of the weights of the indexes $(i=1-18)$

\begin{tabular}{|c|c|c|c|}
\hline Evaluation indexes & Weights & Evaluation indexes & Weights \\
\hline Annual mean precipitation $\left(C_{1}\right)$ & 0.1337 & $\begin{array}{l}\text { Comprehensive standard-reaching percentage of water quality } \\
\left(C_{10}\right)\end{array}$ & 0.026 \\
\hline Annual mean evaporation $\left(C_{2}\right)$ & 0.0941 & Rocky desertification $\left(C_{11}\right)$ & 0.0597 \\
\hline Water production modulus $\left(C_{3}\right)$ & 0.0553 & Intensity coefficient of karst development $\left(C_{12}\right)$ & 0.0452 \\
\hline Drought index $\left(C_{4}\right)$ & 0.0553 & Overburden thickness $\left(C_{13}\right)$ & 0.0343 \\
\hline Exploitation and utilization rate of water resource $\left(C_{5}\right)$ & 0.0816 & Vegetation coverage $\left(C_{14}\right)$ & 0.0394 \\
\hline $\begin{array}{l}\text { Development difficulty coefficient of water resource } \\
\qquad\left(C_{8}\right)\end{array}$ & 0.0408 & Population growth rate $\left(C_{15}\right)$ & 0.0282 \\
\hline Water consumption per capita $\left(C_{7}\right)$ & 0.0816 & Water consumption per unit GDP $\left(C_{16}\right)$ & 0.0564 \\
\hline Proportion of industrial water $\left(C_{8}\right)$ & 0.0361 & Perfect degree of regulations related to water resource $\left(C_{17}\right)$ & 0.0564 \\
\hline Proportion of agricultural water $\left(C_{9}\right)$ & 0.0479 & Mean life expectancy $\left(C_{18}\right)$ & 0.0282 \\
\hline
\end{tabular}

criteria layer are firstly determined. Then, for the four evaluation criteria, the factors are pairwise compared using the expert evaluation method. Consequently, the weighted complementary judgment matrix is acquired, as illustrated in Table 4.

As can be seen, the $\mathrm{CR}$ value computed based on the matrix is less than 0.1 , which implies that the consistency check is passed. Likewise, using the same method for determining the weights in the criteria layer, the weights of indexes are obtained in Table 5 using the AHP.

\section{Comprehensive evaluation of the sustainability of the water resource in the research region}

By combining the calculated weights and the quantization results of the indexes in the research region, the comprehensive evaluation value of the sustainability is acquired based on the Formula (1) as $C=\Sigma A_{i k} \times W_{i k}=1.76$. According to the standard in Table 2, the water resource in the research region exhibits weak sustainability and the main reasons are as follows. With the low forest coverage and thin soil, Zunyi presents serious rocky desertification. Moreover, as there are many mountainous areas, the topographic height difference here is large, thus causing extreme difficulty in exploring the water resource. Furthermore, both per unit GDP and per capita water consumption are large, and meanwhile the regulations related to water resource remain to be improved.

\section{Conclusions}

The exploration and utilization of the water resource in the karst region present special characteristics as uneven distribution of water resource, difficult exploration and sensitivity of the water resource system to the external interferences. Based on the analysis of other evaluation methods, this paper proposes that the sustainability of the water resource in the karst region is supposed to be evaluated from four aspects. They include water resource system, water requirement system, ecosystem and social economic system. Then, from these aspects, the evaluation index system for the sustainability of the water resource in the karst region is established. Meanwhile, the corresponding evaluation method is put forward by combining the AHP method. Afterwards, this method is employed to evaluate the sustainability of the water resource of the typical karst regionZunyi of Guizhou province, China. Furthermore, favorable effect is obtained in the verification based on the regional situation. Therefore, this evaluation method provides a certain basis and reference for evaluating the sustainability of the water resource in karst regions.

Acknowledgments This research was financially supported by China National Natural Science Foundation (Grant Nos. 41430318 and 41272276), the China National Scientific and Technical Support Program (Grant Nos. 201105060-06 and 2012BAB12B03), Guizhou Province Science and Technology Agency Foundation (qian ke he LH zi[2014]7617), Guizhou University Introducing Talents Research Foundation (2014-61), Guizhou Province Geological Exploration Fund (Guizhou karst groundwater system functions sustainable utilization)

Open Access This article is distributed under the terms of the Creative Commons Attribution 4.0 International License (http:// creativecommons.org/licenses/by/4.0/), which permits unrestricted use, distribution, and reproduction in any medium, provided you give appropriate credit to the original author(s) and the source, provide a link to the Creative Commons license, and indicate if changes were made.

\section{References}

Bossel H (1999) Indicators for sustainable development: theory, method, applications. International Institute for Sustainable Development, Winnipeg 
Chu WH, Yan GQ, Su WC (2008) Study on water resources sustainable utilization of karst river basins. Shui Li Xue Bao 39(6):753-757

Giacomoni MH, Zechman EM (2011) Assessing sustainability of integrated urban water resources systems through a complex adaptive systems approach. In: World Environmental and Water Resources Congress, ASCE, 2844-2851

Haider H, Singh P, Ali W, Tesfamariam S, Sadiq R (2015) Sustainability evaluation of surface water quality management options in developing countries: multicriteria analysis using fuzzy UTASTAR method. Water Resour Manag 29(8):2987-3013

Kuzdas C, Wiek A, Warner B, Vignola R, Morataya R (2014) Sustainability appraisal of water governance regimes: the case of Guanacaste, Costa Rica. Environ Manag 54(2):205-222

Loucks DP (2000) Sustainable water resources management. Water Int 25(1):3-10

Rijsberman MA, De Ven V, Frans HM (2000) Different approaches to assessment of design and management of sustainable urban water system. Environ Impact Assess Rev 129(3):333-345
Roy SB, Ricci PF, Summers KV, Chung CF, Goldstein RA (2015) Evaluation of the sustainability of water withdrawals in the United States, 1995-2025. J Am Water Resour Assoc 41(5):1091-1108

Saaty TL (1977) A scaling method for priorities in hierarchical structures. J Math Psychol 15(3):234-281

Saaty TL (1980) The analytic hierarchy process. McGraw-Hill, New York

Simonovic SP, Kundzewicz Z, Rosbjerg D, Takeuchi K (1995) Modeling and management of sustainable basin-scale water resource systems. IAHS Press, Wallingford

Xiao L, Han XJ, Dong Z (2011) The sustainability evaluation model of irrigation district groundwater resources carrying capacity based on catastrophe theory. In: 5th international symposium on integrated water resources management, Nanjing, China, IWRM 2010 and the 3rd international symposium on methodology in hydrology, pp 241-247

Zhang LP, Zhu ZL, Deng LJ (2004) Present situation of and problems in water resource evaluation indicator systems in China. Resour Surv Assess 21(4):5-8 